\title{
Regulation and Control of Algorithmic Codes - a Necessity of our Times (?)
}

Ewa Rott-Pietrzyk

<ewa.rott-pietrzyk@us.edu.pl>

KATOWICE, Poland

Dariusz Szostek

$<$ dariusz.szostek@szostek-bar.pl>

KATOWICE, OPOLE, Poland

Marek Świerczynski

<m.swierczynski@uksw.edu.pls

WARSZAWA, Poland

Every technology has a good and a bad side, and the use people make of the fruits of their knowledge depends on themselves ${ }^{1}$

Stanisław Lem

\section{Abstract}

For many years, the issue of algorithmic codes and implementation was not more widely addressed by lawyers. The development of blockchain, smart contract but above all artificial intelligence has changed this situation. Algorithms not only support human work, but more and more often replace human actions, including decisions affecting the rights of individuals. There is an emerging need to control and verify algorithmic codes. In this article we intend to show what changes in this area are taking place in Europe and inspire other countries.

Keywords:

Algorithm, software, artificial intelligence, blockchain, implementation of law in codes.

1 While 2021 is Lem's year, it is symbolic to remind readers that Stanisław Lem's statement can be found in his collection of his short stories titled: Dziury w całym, Znak 1997 [in English: A hole in the whole]. 


\section{Introduction}

One of the most serious challenges, not so much for the internet or the development of the digital economy, but more broadly for the maintenance of human rights at the current level, is the need to control not only the content placed on the Internet (e.g. hate speech, sexual abuse of children, violation of personal rights, etc.), but also the algorithmic codes, which are no longer just the carriers of such content, but tools that have an increasing influence on people and their rights. ${ }^{2}$ At the end of the last century, Prof. L. Lessig published a concept of law functioning as an algorithm - law incorporated into software - which seemed futuristic at the time, but which is now being implemented - the law consisting of "puzzles" that can be combined and shaped in cyberspace. ${ }^{3}$ Reading the chapters of this monograph indicates the increasing role of algorithms. This not only refers to the shaping of cyberspace, but also to their direct impact on people and their rights. We are no longer just witnessing pilot projects or academic concepts, but actually implemented IT systems in which human language (written or spoken) is transformed into algorithmic codes readable by machines equipped with processors and directly executed by them. This process has been increasingly taking place, but in a way that can be directly perceived by humans, transcribing computer code into symbols, letters, words, phrases and sentences ${ }^{4}$ A provision of a law or a contract is beginning to function as a computer program, rather than as a text of legal provisions consisting of letters and grammatical signs presented in natural language. ${ }^{5}$ Law and technology are increasingly interacting with

2 See also Robert Seyfert, 'Algorithms as regulatory objects' (2021) Information, Communication \& Society 2021.

3 Lawrence Lessig, 'Code and other laws of cyberspace' ( Basic Books 1999) $3 \mathrm{ff}$.

4 Anderas Wiebe, Die elektronische Willenserklarung (Tubingen 2002) 350; see also Mirko Pečarič ‘Lex Ex Machina: Reasons For Algorithmic Regulation' (2021) Masaryk University Journal of Law and Technology $85 \mathrm{ff}$.

5 For more on the transcription of spoken language into algorithmic codes, see: Michał Araszkiewicz, 'Algorithmization of legal thinking. Models, possibilities, limitations' in Dariusz Szostek (ed) Legal Tech (C.H. Beck 2021) 57-83. 
each other. ${ }^{6}$ Code is the architecture of cyberspace and pieces of code are the building material of this architecture. Everything we see online is delivered through code, only code can allow the regulation of social rules in cyberspace. In this way, code functions as a regulator of cyberspace. ${ }^{7}$

It was more than 20 years ago that L. Lessig drew attention to the problem of algorithmic code as a regulator:

"Every age has its potential regulator, its threat to liberty. Our founders feared a newly empowered federal government; the Constitution is written against that fear. John Stuart Mill worried about the regulation by social norms in nineteenth-century England; his book On Liberty is written against that regulation. Many of the progressives in the twentieth century worried about the injustices of the market. The reforms of the market, and the safety nets that surround it, were erected in response. Actuality this regulator is code--the software and hardware that make cyberspace as it is. This code, or architecture, sets the terms on which life in cyberspace is experienced. It determines how easy it is to protect privacy, or how easy it is to censor speech. It determines whether access to information is general or whether information is zoned. It affects who sees what, or what is monitored. In a host of ways that one cannot begin to see unless one begins to understand the nature of this code, the code of cyberspace regulates." 8

Even that early, he pointed towards the need for the certification and authorisation of algorithms. Nowadays, when algorithms are not only creating cyberspace, but also making decisions that have an effect on human life, implementing legal regulations in themselves ${ }^{9}$ and increasingly boldly

6 Rohan Nanda, Giovanni Siragusa, Luigi Di Caro, Guido Boella, Lorenzo Grossio, Marco Gerbaudo and Francesco Costamanga, 'Unsupervised and supervised text similarity systems for automated identification of national implementing measures of European directives' (2019) 27 Artificial Intelligence and Law Romain Boulet, Pierre Mazzega and Danièle Bourcier 'Network approach to the French system of legal codes part II: the role of the weights in a network' (2018) 26 Artificial Intelligence and Law $23 \mathrm{ff}$.

7 Sergii Schrebak, 'Integrating Computer Science into Legal Discipline: The Rise of Legal Programming' (SSRN, 15 September 2014) $4<$ https://papers.ssrn.com/sol3/p apers.cfm?abstract_id=2496094 $>$ accessed 5 July2021.

8 Lawrence Lessig, 'Code is Law. On Liberty in Cyberspace'(Harvard Magazine, 2000), <https://www.harvardmagazine.com/2000/01/code-is-law-html > accessed 6 July 2021.

9 Sergii Schrebak, 'Integrating Computer Science into Legal Discipline: The Rise of Legal Programming' (SSRN, 14 September 2014) $1<$ https://papers.ssrn.com/sol3/p apers.cfm?abstract_id=2496094 $>$ accessed 5 July 2021. 
participating in law enforcement ${ }^{10}$ or even issuing court judgments, their control becomes important and even more necessary, both at the regional level (EU), but also, in our opinion, at the international level (Convention).

It seems to be a paradox that we humans are building a powerful tool (covering various NewTech instruments), making great progress in coming up with improvements and it is only as almost the "last step" that we notice that its regulation has grown not only necessary, but urgent. Therefore it seems that this is a good time, as it is possibly the last time, to create some regulations that protect many values in the human environment in the era of new technologies that is influencing almost all (if not all) spheres of life. The need for the certification and authorisation of algorithms is very urgent at both national and international level, not only local (EU) but global. There is a question as to what would be the best body to establish that? And what would be the best way to create it (in terms of procedure, methods and content)? For now, the creation of universal norms at global level (no matter their nature: binding force or soft law) is kind of fiction in the near future. However, some solutions have to be found. What we have currently on the European stage is not sufficient, but it can be perceived as a vital step. It sounds banal, but there is no return to the old world, and the new world needs to have some protection against the products of its own making. In the frame of Europe, the regulatory process has started, which is itself of great value.

The aim of this article is to present the European approach, way of thinking and dealing with the issue covered in its title with some general reflections on the need for a regulation and control over algorithmic codes.

10 An example of this is the increasing prevalence of smart contracts. Daniel Hellwig, Goran Karlic and Arnd Huchzermeier, 'Build Your Own Blockchain' (Springer 2020) 74 ff., Maria G. Vigliotti and Haydn Jones, The Executive Guide to Blockchian (Pagrave Macmillan 2020) 133; Eranga Bandara, Wee Keong, Nalin Ranasinghe and Kasun de Zoysa, 'Smart contract Made Smart' in (ed) Zibin Zheng, HongNing Dai, Mingdong Tang and Xiangping Chen, Blockchain and Trustworthy System (Springer 2020) 431; Robert Wilkens and Richard Falk, Smart Contracts, Grundlagen, Anwedungsfelder und rechtliche Aspekte (Springer 2019) 3 ff; Riccardo de Caria, 'Definitions of Smart Contracts' in Larry A. DiMatteo, Michel Cannarsa and Cristina Poncibo (eds) Smart contracts, blockchain technology and digital platforms (Cambridge Law Handbooks 2019) 19-36. 


\section{Control over codes at EU level}

The European Union has recognised the problem of code control and has taken a great deal of legislative action in this area. In a number of documents it has pointed to the need for transparency and accountability initially of algorithms acting as AI, and eventually also of other algorithms. It has been pointed out, including in the resolution on civil law provisions in the field of robotics and AI adopted by the European Parliament on 16 February 2017, in the resolution of the European Parliament and the Council of 20 October 2020 containing recommendations to the European Commission on a civil liability regime for artificial intelligence (AI), in the White Paper for AI, ${ }^{11}$ and more comprehensively in the Report Artificial Intelligence and Fundamental Right (2020), ${ }^{12}$ that, when creating algorithms, it is necessary to take into account: human dignity, the right to privacy and data protection, access to justice, equality and non-discrimination and consumer protection. A recent European Commission report "Safety over Liability Related Aspects of Software" prepared by Prof. Christiane Wenderhorst ${ }^{13}$ identifies recommendations for the regulation of algorithms as follows: 1 . Introduce a new semi-horizontal and risk-based regime on software safety (accompanied by further steps to modernise the safety-related acquis), 2. Revise the Product Liability Directive, 3. Introduce a new regulatory framework for AI, 4. Introduce a new instrument on AI liability, and 5. Continue the digital fitness check of the whole acquis. Particularly worth quoting is the justification to introduce a new semi-horizontal and risk-based regime on software safety:

"The European legislator should introduce a new regime on software safety. This regime would be semi-horizontal in nature as it would apply only to software, but to all software (e.g. whether embedded, accessory or standalone), in a very broad and technologically neutral sense and including, e.g., SaaS. It would overcome shortcomings in the existing safety legislation, which does either not cover software, in particular not standalone software, or is poorly equipped to deal with software. The European legislator might

$11<$ https://ec.europa.eu/info/sites/default/files/commission-white-paper-artificial-inte lligence-feb2020_en.pdf $>$ accessed 7 July 2021.

$12<$ https://fra.europa.eu/sites/default/files/fra_uploads/fra-2020-artificial-intelligence _en.pdf $>$ accessed 8 July 2021.

13 See also Christine Wendehorst's approach in her article, 'Strict Liability for AI and other Emerging Technologies'(2020) 11, 2 Journal of European Tort Law: https://www.degruyter.com/journal/key/jetl/html, 150-180. 
thus consider introducing a new Software Safety Directive (SSD), which would have to be accompanied by selected further steps towards modernisation of the safety-related acquis.

The relationship of the SSD with existing and future sectoral legislation would be one of complementarity. The SSD would be dealing with cross-cutting issues such as the delineation between products with software elements, add-on software for other products, and standalone software that otherwise interacts with other products, and the division of responsibilities between the different producers in either case. It would deal with privacy by design, cybersecurity (until/unless addressed by other acts developed under the Cybersecurity Act), post-market surveillance duties, issues arising in the context of updates, and similar questions."

The European Union goes further than simply referring to the regulation and control of algorithmic codes in its reports and recommendations. In its most recent legislative proposals, it explicitly proposes appropriate solutions. At present, the following ideas deserve particular attention: Proposal for a Regulation Of The European Parliament And Of The Council On Machinery Products, ${ }^{14}$ Proposal For A Regulation Of The European Parliament And Of The Council Laying Down Harmonised Rules On Artificial Intelligence (Artificial Intelligence Act) And Amending Certain Union Legislative Acts, ${ }^{15}$ and Proposal of Regulation of the European Parliament and the Council amending Regulation (EU) No 910/2014 a regards establishing o framework for a European Digital Identity. ${ }^{16}$

The broadest proposal for the regulation of algorithmic codes is the proposed Artificial Intelligence Act. Its scope covers not only AI in the narrow sense, but also other codes indicated in its Annex 1. According to the proposed definition in Article 3(1), artificial intelligence system (AI system) means software that is developed with one or more of the techniques and approaches listed in Annex I and can, for a given set of human-defined objectives, generate outputs such as content, predictions, recommendations, or decisions influencing the environments they interact with. Whereas according to Annex 1, AI includes: machine-learning approaches, including supervised, unsupervised and reinforcement learning, using a wide variety of methods including deep learning; logic- and knowledge-based approa-

$14<$ https://ec.europa.eu/docsroom/documents/45508> accessed 5 July 2021.

15 <https://eur-lex.europa.eu/legal-content/EN/TXT/?uri=CELEX:52021PC0206> accessed 6 July 2021.

$16<$ https://op.europa.eu/pl/publication-detail/-/publication/5d88943a-c458-11eb-a92 5-01aa75ed71a1/language-en/format-PDF/source-search>accessed 6 July 2021. 
ches, including knowledge representation, inductive (logic) programming, knowledge bases, inference and deductive engines, (symbolic) reasoning and expert systems; statistical approaches, Bayesian estimations, as well as search and optimization methods. This means that, once the regulation comes into force, not only AI, but also a number of other algorithms may be covered by the regulation.

Some very interesting proposals, indirectly introducing code control, are contained in the proposal for an amendment of Regulation eIDAS (beyond eIDAS2). The European Commission proposes to introduce into the European legal order a definition of "electronic ledger" where "electronic ledger" means a tamperproof electronic record of data, establishing the authenticity and integrity of the data it contains, the accuracy of the date and time, and the chronological ordering. It is proposed to link the legal effects to the entry in the electronic register. As proposed in Article $45 \mathrm{~h}$ of eIDAS2, an electronic ledger would not be denied legal effect and admissibility as evidence in legal proceedings solely on the grounds that it is in an electronic form, or that it does not meet the requirements for qualified electronic ledgers. More relevant is the introduction of a legal presumption linked to an entry, but not so much to a 'ordinary' electronic ledger as to a qualified electronic ledger. As proposed in Article 45h(2), a qualified electronic ledger would enjoy the presumption of the uniqueness and authenticity of the data it contains, of the accuracy of the date and time, and of the sequential chronological ordering within the ledger. In other words, it is proposed to equate the entry of data into a qualified register kept by a qualified entity providing certification services as a trust service with the original of a document, or even more broadly, with the original of data not necessarily constituting a document in the traditional sense. The presumption will only apply to electronic registers previously verified and audited as a qualified trusted service. Qualified electronic ledgers must meet the following requirements: (a) they are created by one or more qualified trust service provider or providers; (b) they ensure the uniqueness, authenticity and correct sequencing of data entries recorded in the ledger; (c) they ensure the correct sequential chronological ordering of data in the ledger and the accuracy of the date and time of the data entry; (d) they record data in such a way that any subsequent change to the data is immediately detectable. This concept is not novel. Similar legal solutions already exist in many countries, e.g. Malta, Singapore and the State of New York in the USA.

The Proposal for a Regulation of The European Parliament And Of The Council On Machinery Products, as proposed in Annex 1, considers as hazardous products, among other things, software ensuring safety functions, 
including AI systems and machinery embedding AI systems ensuring safety functions. As in the proposed AI Act, these systems will be subject to control and supervision depending on the level of risk associated with them.

These are not the European Commission's only proposals for legislation involving the control of algorithms. They are only an example of the legislative changes taking place in this area.

\section{Artificial Intelligence Act \& Council of Europe}

\subsection{General remarks}

It is not only the European Union that is taking action on code control regulation. The Council of Europe has also taken initiatives in this area. The draft Artificial Intelligence Act aims to build an ecosystem of trust based on a legal framework for trustworthy artificial intelligence. As noted above, this includes the regulation and control of algorithmic codes. It contributes to ensuring that users trust and accept new solutions based on algorithmic codes and that entrepreneurs are more willing to develop such solutions. ${ }^{17}$ It also addresses challenges such as the black box effect, ${ }^{18}$ complexity, bias, unpredictability and the possible autonomy of algorithmic code-based solutions.

It is also clear that the development of innovations based on algorithmic codes, based to an even wider extent than just on AI itself, requires

17 Jenna Burrell, 'How the Machine 'Thinks': Understanding Opacity in Machine Learning Algorithms' (2016) 3, 1 Big Data \& Society <https://papers.ssrn.com/sol 3/papers.cfm?abstract_id=2660674> accessed 12 July 2021.

18 Rosario Girasa, Artificial Intelligence as a Disruptive Technology. Economic Transformation and Government Regulation (Palgrave Macmillan 2020) 4; see also Octavio Loyola-González: https://www.researchgate.net/profile/Octavio-Loyola-Gonzal ez, 'Black-Box vs. White-Box: Understanding Their Advantages and Weaknesses From a Practical Point of View' IEEE Access; Yavar Bathaee, 'The Artificial Intelligence Black Box And The Failure Of Intent And Causation' (2018) 31, 2 Harvard Journal of Law \& Technology 889-938. 
convergence with the proposed Data Governance Act, ${ }^{19}$ the Open Data Directive $^{20}$ and other initiatives that are part of the European Data Strategy. ${ }^{21}$

The developers of the draft AIA aim to ensure its consistency with the provisions of the Charter of Fundamental Rights of the European Union and applicable Union secondary law. In particular, in the area of algorithmic codes, it is crucial to ensure consistency with the provisions of the General Data Protection Regulation (Regulation (EU) 2016/679) and with the provisions of the Enforcement Directive (Directive (EU) 2016/680). Indeed, the draft Regulation complements the provisions of these acts by introducing a set of harmonised rules applicable to the design, development and use of algorithmic codes.

The draft also supplements the current legislation with specific requirements to minimise the risk of algorithmic discrimination, in particular with regard to the design and quality of datasets used to develop solutions based on algorithmic codes. This involves the introduction of specific testing, risk management, documentation and oversight obligations for algorithmic codes.

\subsection{A risk-based approach}

When regulating algorithmic codes, there should be a clear preference for a risk-based approach. The use of a risk-based framework is preferable to a general regulation of all possible solutions based on algorithmic codes. Risks and threats should be determined on a case-by-case and sector-by-sector basis. Risks should also be calculated taking into account the impact on users' rights and safety. Risks should be calculated taking into account the impact on the rights and safety of users

For these reasons, the draft AIA sets out harmonised rules for the development, marketing and use of algorithmic code-based solutions in accordance with a proportionate risk-based approach.

This approach entails detailed solutions involving algorithmic codes.

19 Proposal for a Regulation on European data management (Data Management Act) $\operatorname{COM}(2020) 767$.

20 Directive (EU) 2019/1024 of the European Parliament and of the Council of 20 June 2019 on open data and re-use of public sector information, PE/28/2019/REV/1 [2019] OJ L172/56.

21 Commission Communication 'A European Data Strategy', $\operatorname{COM}(2020) 66$ final. "A European data strategy", $\operatorname{COM}(2020) 66$ final. 
First of all, it should be stressed that the project has adopted a very broad definition of artificial intelligence, which also includes algorithmic codes. This is because the definition is based on the key functional characteristics of software, in particular, taking into account a set of human-defined goals, the ability to generate outputs such as content, predictions, recommendations or decisions that affect the environment with which the system interacts, whether physical or digital. Algorithmic code-based systems can be designed to operate at various levels of autonomy and can be used as stand-alone solutions or as part of a product, regardless of whether the system is physically integrated into the product (embedded) or whether it serves a product function although not integrated into it (non-embedded). The definition is complemented by a list of specific techniques and approaches used in the development of algorithmic codes. However, it should be stipulated that this list should be updated in the perspective of market developments and technological progress in the field of algorithmic codes.

The draft AIA also provides for a prohibition on certain particularly harmful practices using algorithmic codes that are contrary to EU values, and proposes specific restrictions and safeguards for certain applications of remote biometric identification systems for law enforcement purposes.

Obligations are also placed on the providers and users of such solutions to ensure security and respect for existing legislation on the protection of fundamental rights.

The proposed rules will be enforced through a governance system at Member State level based on already existing structures and a cooperation mechanism at EU level, for which a European AI Council will be established. Furthermore, the draft proposes additional measures to support innovation, including in particular regulatory sandboxes and other measures to reduce the regulatory burden and to support small and medium-sized enterprises and start-ups.

\subsection{Evaluation of Artificial Intelligence Act}

The introduction of new EU legislation concerning algorithmic coding entails a high risk of overlap with existing legislation, conflicting obligations and overregulation in this area. It is therefore crucial to introduce a proportionate, technology-neutral regulatory framework.

It must be accepted that the nature of algorithmic codes, which are often based on large and diverse data sets and which can be used in virtually any product or service traded freely in the internal market, means 
that individual countries will not be able to draw up a coherent regulation on their own.

The potential thicket of divergent national laws will hinder the marketing of products and services based on algorithmic codes. It will be ineffective in ensuring security and protecting fundamental rights. A national approach to solving these issues will only create additional legal uncertainty and barriers and will slow down the introduction of new technologies into the market.

These objectives can be better achieved at EU level. This avoids fragmenting the Single Market into potentially conflicting national frameworks preventing the free circulation of AI-enabled goods and services.

The choice of a regulation as a legal instrument is justified by the need for the uniform application of the new rules, prohibitions on certain harmful practices associated with the use of algorithmic codes and the classification of certain solutions based on them. A regulation, as an instrument directly applicable under Article 288 TFEU, will reduce legal fragmentation and facilitate the development of the Single Market. This can be achieved, in particular, by introducing a harmonised set of essential requirements for algorithmic code-based solutions and obligations for their providers and users.

It should be accepted that the draft AIA sets out a balanced and proportionate horizontal regulatory approach to algorithmic codes that is limited to the minimum requirements necessary to address the risks associated with their use, without unduly restricting or impeding technological development or otherwise causing a disproportionate increase in the cost of bringing new products and services to market.

\subsection{The Council of Europe's role in regulating algorithmic codes}

The Council of Europe plays a key role in ensuring the further development of algorithmic code-based solutions at the global level, ensuring their compatibility 22 with human rights protection standards .

The resulting output can be divided into four areas: 1) Recommendations, guidelines and other instruments issued by the Council of Europe

22 A study of the implications of advanced digital technologies (including AI systems) for the concept of responsibility within a human rights framework. Prepared by the Expert Committee on human rights dimensions of automated data processing and different forms of artificial intelligence (MSI-AUT). Rapporteur: Karen Yeung, DGI(2019)05. 
bodies or committees established to look into AI - recommendations, guidelines and other instruments issued by Council of Europe bodies or AI committees; recommendations of the Committee of Ministers to Member States on the human rights impacts of algorithmic systems; recommendations on developing and promoting digital citizenship education; a declaration of the Committee of Ministers on the manipulative capabilities of algorithmic processes; a European Ethical Charter on the use of artificial intelligence in judicial systems and their environment; and a recommendation of the Parliamentary Assembly of the Council of Europe about technological convergence, artificial intelligence and human rights; 2) Studies, reports and conclusions of key events - a feasibility study on the establishment of a certification mechanism for artificial intelligence tools and services (CEPEJ, 8 December 2020); Artificial Intelligence in the Audiovisual Industry - a summary of a workshop (European Audiovisual Observatory, 17 December 2019); Artificial Intelligence and its Impact on Young People - a seminar report (European Youth Centre, 4-6 December 2019); proceedings of the Roundtable on Artificial Intelligence and the Future of Democracy (CDDG-Bu(2019)17, Democratic governance department, 20 September 2019); conclusions from the conference "Governing the Game Changer - impacts of artificial intelligence development on human rights, democracy and the rule of law" (Finnish Presidency of the Committee of Ministers and Council of Europe, Helsinki, 26-27 February 2019); 3) Reports of the Parliamentary Assembly of the Council of Europe: a report on "Artificial Intelligence and Labour Markets: Friend or Foe?"; a report on Artificial Intelligence in Healthcare: medical, legal and ethical challenges ahead; a report on Justice by Algorithm (the role of artificial intelligence in policing and criminal justice systems); a report on Preventing Discrimination Caused by the Use of Artificial Intelligence; a report on the Need for Democratic Governance of Artificial Intelligence, 4) other initiatives: a concept note on Artificial intelligence and Criminal Law Responsibility in Council of Europe Member States - the case of automated vehicles; the development of a recommendation and a study on the Impacts of Digital Technologies on Freedom of Expression; youth policy standards and other institutional responses to newly emergent issues affecting young people's rights and transition to adulthood, including AI; a report on AI in the Audiovisual Industry; a draft declaration of the Committee of Ministers of the Council of Europe on the risks of compu- 
ter-assisted or artificial-intelligence-enabled decision making in the field of the social safety net. ${ }^{23}$

The importance of work on algorithmic codes is underlined by the Council of Europe creating the Ad hoc Committee on Artificial Intelligence (hereinafter: CAHAI) in 2019. ${ }^{24}$ The purpose of CAHAI is to examine, based on broad stakeholder consultation, the issue of artificial intelligence, based on the Council of Europe's promoted standards on human rights, democracy and the rule of law. ${ }^{25}$

In summary, the Council of Europe acquis to date takes into account current needs arising from the use of algorithmic code-based tools. The guidelines of the Council of Europe, as an instrument of soft law, lend themselves to easy changes and additions, along with technological progress. Code-based technologies are global in nature. Multilateral cooperation among countries is therefore required to establish uniform international standards.

23 To the details see: $<$ https://www.coe.int/en/web/artificial-intelligence/work-in-pro gress $>$ accessed 12 July 2021.

24 <https://rm.coe.int/cahai-2020-2021-rev-en-pdf/16809fc157> accessed 12 July2021.

25 The CAHAI is composed of: representatives of the 47 member states, appointed by their governments, who have recognised expertise in digital governance and the legal implications of various forms of AI; representatives of observer states (Canada, the Holy See, Israel, Japan, Mexico and the United States of America); and representatives of other Council of Europe bodies, in particular the Secretariat of the Parliamentary Assembly, the Office of the Commissioner for Human Rights and the intergovernmental commissions dealing with issues related to AI. Representatives of other Council of Europe bodies, in particular the Secretariat of the Parliamentary Assembly, the Office of the Commissioner for Human Rights and the intergovernmental commissions dealing with issues related to artificial intelligence; representatives of other international and regional organisations working in the field of artificial intelligence, such as the EU, the UN (in particular UNESCO), the OECD, the OSCE; representatives of the private sector, including companies and associations with which the Council of Europe has exchanged letters in the framework of the Digital Business Partnership; representatives of civil society, research and academic institutions who have been admitted by CAHAI as observers. More: $<$ https://www.coe.int/en/web/artificial-intelligence/ cahai\#\{02266693418\%22:[0]\}> accessed 12 July 2021; <https://rm.coe.int/list-of-ca hai-members-web/16809e7ffd $>$ accessed 12 July 2021. 


\section{Conclusions}

Over the last ten years, it has become obvious that the legal framework must be extended into the various uses of automated decision-making software creeping into every layer of our lives. As the evidence continues to accumulate, it is also obvious that automation does not equal justice, and the greater the autonomy of the autonomous system, the greater the possibility for creating a prejudicial framework that would discriminate against specific groups of people. ${ }^{26}$ It is an undisputable issue that the same prejudices and biases that have haunted society for decades, could now possibly be incorporated into pseudo-objective algorithms. ${ }^{27}$

This can be announced in a symbolic way: welcome to a new world where mankind is joining forces with machines through digital technology(!). ${ }^{28}$ As we noted in the introduction, there is no return to the old world. However, the new (digitalised) world has to be devised in a proper way so as not to destroy its creator. This world covers a new system of social ordering, in other words - algorithmic regulation. This regulation refers to decision-making systems that regulate the domain of activity in order to manage risk or alter behaviour through the continual computational generation of knowledge by collecting data in real time on a continuous basis, emitted directly from numerous dynamic components concerning the regulated environment, in order to identify and, if necessary, automatically refine the system's operations to attain a pre-specified goal. ${ }^{29}$ In other words, it employs the idea of controlling a population by means of feedback mechanisms, based on the threefold requirement of standard-setting, monitoring and behaviour modification. It is grounded and explained in a behaviourist perspective on human intercourse and

26 Terence Shin, 'Real-life examples of Discriminating Artificial Intelligence' (Towards Data Science, 4 June 2020) <https://towardsdatascience.com/real-life -examples-of-discriminating-artificial-intelligence-cae395a90070> accessed 12 July 2021.

27 Alina Köchling and Marius C. Wehner, 'Discriminated by an algorithm: a systematic review of discrimination and fairness by algorithmic decision-making in the context of HR recruitment and HR development' (2020) 13 Bus Res 795-848 . $<$ https://doi.org/10.1007/s40685-020-00134-w> accessed 12 July 2021.

28 These words were used by Lina Willatte in the foreword to Jérôme Béranger's book titled: The Algorithmic Code of Ethics: Ethics at the Bedside of the Digital Revolution, vol. 2, as a part of Science and New Technologies Series. Technological Prospects and Social Applications Set, London-Hoboken 2018, p. vii.

29 For more detail, see Karen Yeung, 'Algorithmic regulation: A critical interrogation’ (2017) 12, 4 Regulation \& Governance 505-523. 
displays an external perspective on human action. ${ }^{30}$ At a first glance, this may sound not very optimistic, taking into consideration the possible negative effects of human freedoms and rights. Humankind as a species is at this point. ${ }^{31}$ We could contest the algorithmic regulation doing nothing or undertake serious action. In our opinion, serious action is absolutely essential. During this serious action, two areas of consideration are absolutely vital: the area of law and the area of ethics. Both areas have to be combined. There are important voices establishing the extent to which ethics could create a background for the legal regulations concerning the regulation and control of algorithmic codes. 32

Proper testing of new solutions implies built-in contestation - in science as in law. Therefore new ideas, concepts and proposals always provoke heated discussion, critique and contestation. This all is natural. However, in our opinion it cannot stop nor delay the mentioned serious action that has already started and is continued at the European level, as we present in the article. It was not our intention to discuss specific solutions proposed in all the various documents that have been prepared in Europe. We intend to underline the urgent need to regulate and control algorithmic codes using every lifesaving measure currently at our disposal, for example using soft law or various legislative proposals. This creates a background for binding solutions at the level of the European Union and the Member States, and may simultaneously inspire national legislators to start work in internal legislation. ${ }^{33}$ Therefore, even if what we have now at the European level is not perfect and can be perceived by some to be chaotic, or even negative for the classic civilists, the action that has been commenced cannot be stopped. Instead, it should be supported by scientists and practitioners rep-

30 For more detail, see Mireille Hildebrandt, 'Algorithmic regulation and the rule of law' (2018) 376, 2128 Philosophical Transactions of the Royal Society A Mathematical, Physical and Engineering Sciences $<$ https://royalsocietypublishing.org/do i/pdf/10.1098/rsta.2017.0355> accessed 12 July 2021.

31 See also Karen Yeung, Algorithmic regulation (footnote 27), who quotes Tim O'Reilly, CEO of O'Reilly Media Inc. 2013, p. 291 and takes his sentence as her motto: It's time for government to enter the age of big data. Algorithmic regulation is an idea whose time has come."

32 A good example of this writing is Jérôme Béranger's book titled: The Algorithmic Code of Ethics: Ethics at the Bedside of the Digital Revolution (footnote 28).

33 The same is with the case of the Draft Common Frame of Reference (DCFR) which states a model law for many national legislators, for example Polish, see Ewa Rott-Pietrzyk and Mateusz Grochowski, 'Regulacja umów o pośrednictwo w DCFR (wzorcem dla ustawodawcy polskiego?)' (2017) 3 Transformacje Prawa Prywatnego 49-81. 
resenting a wide range of disciplines. This is definitely not only a matter of action (in terms of producing law) taken by the lawyers and EU officials, it is a serious interdisciplinary task for a large number individuals who could be engaged for the benefit of all.

The conclusion can be covered in one sentence - we should regulate algorithms, otherwise the algorithms will end up regulating and controlling us. It is obvious that we cannot go back to a world without algorithms, but we can overcome algorithmic hegemony. ${ }^{34}$ Thinking this way, mankind will try to follow Stanisław Lem's thought: Every technology has a good and a bad side, and the use people make of the fruits of their knowledge depends on themselves.

34 See also the position of Fabian Ferrari and Mark Graham, 'Fissures in algorithmic power: platforms, code, and contestation’ (2021) Cultural Studies 13, 14. 